\title{
SUSCEPTIBILITY OF Candida spp. ISOLATED FROM BLOOD CULTURES AS EVALUATED USING THE M27-A3 AND NEW M27-S4 APPROVED BREAKPOINTS
}

\author{
Edileusa Rosa dos SANTOS(1,2), Camila F. DAL FORNO(2), Mari Glei HERNANDEZ(1,2), Thaís Felli KUBIÇA(1), Tarcieli P. VENTURINI(1), \\ Francieli CHASSOT(1), Janio M. SANTURIO(3) \& Sydney Hartz ALVES(1,3)
}

\begin{abstract}
SUMMARY
The high mortality rates associated with candidemia episodes and the emergence of resistance to antifungal agents necessitate the monitoring of the susceptibility of fungal isolates to antifungal treatments. The new, recently approved, species-specific clinical breakpoints (SS-CBPs)(M27-S4) for evaluating susceptibility require careful interpretation and comparison with the former proposals made using the M27-A3 breakpoints, both from CLSI. This study evaluated the susceptibility of the different species of Candida that were isolated from candidemias based on these two clinical breakpoints. Four hundred and twenty-two isolates were identified and, among them, C. parapsilosis comprised 46.68\%, followed by C. albicans (35.78\%), C. tropicalis (9.71\%), C. glabrata (3.55\%), C. lusitaniae (1.65\%), C. guilliermondii (1.65\%) and C. krusei (0.94\%). In accordance with the M27-A3 criteria, 33 (7.81\%) nonsusceptible isolates were identified, of which 16 (3.79\%) were resistant to antifungal agents. According to SS-CBPs, 80 (18.95\%) isolates were non-susceptible, and $10(2.36 \%)$ of these were drug resistant. When the total number of non-susceptible isolates was considered, the new SS-CBPs detected 2.4 times the number of isolates that were detected using the M27-A3 interpretative criteria. In conclusion, the detection of an elevated number of non-susceptible species has highlighted the relevance of evaluating susceptibility tests using new, species-specific clinical breakpoints (SS-CBPs), which could impact the profile of non-susceptible Candida spp. to antifungal agents that require continuous susceptibility monitoring.
\end{abstract}

KEYWORDS: Resistance; SS-CBPs; CLSI breakpoints; Antifungals; Candidemia.

\section{INTRODUCTION}

Candidemia occupies a prominent place among the invasive fungal infections ${ }^{1,2,3,6,20}$. This infection is among the most common fungal infections in hospitalized patients and leads to a long hospital stay, increased hospital costs ${ }^{14}$ and a mortality rate reaching $61 \%$ in Brazil $^{10}$.

Several conditions are associated with the development of candidemia, such as the following: a) the use of antibacterial agents; b) the presence of a central venous catheter; c) the use of type 2 histamine receptor blockers $\left(\mathrm{H}_{2}\right)$; d) total parenteral nutrition; e) admission at an intensive care unit (ICU); f) the use of corticosteroids; g) surgeries; h) previous hospitalization; and i) colonization by Candida $a^{2,3,9,16}$.

Among the causes of high mortality rates that are observed for candidemia is the failure of antifungal therapies, which is often due to the emergence of resistance ${ }^{10}$.

Similar to the resistance phenomena that are observed when using antibacterial agents, antifungal resistance can be innate or secondary to the antifungal agents that are used ${ }^{13}$. Additionally, the limited number of systemic antimycotics that are available has contributed to resistance, first against flucytosine and then against fluconazole. Furthermore, multiple studies have shown that cross-resistance may cover other azole class antifungals ${ }^{18}$.

The spectrum of Candida species isolated from hospitals is directly linked to the type of patient, geographic location and most commonly used procedures; and, overall, it can define the susceptibility profile to antifungal agents ${ }^{6,23}$.

From a temporal perspective, antifungal agents used for candidemia have included amphotericin B, flucytosine associated with amphotericin $\mathrm{B}$, fluconazole and, more recently, voriconazole and echinocandins ${ }^{15}$.

Since 1997, susceptibility tests of Candida to antifungal agents have been in use due to the standardization developed by the National Committee for Clinical Laboratory Standards (NCCLS-M27-A) ${ }^{13}$. The Antifungal Susceptibility Testing Subcommittee of the European Committee on Antibiotic Susceptibility Testing (EUCAST) ${ }^{25}$ also has a

(1) Post-Graduate Program in Pharmaceutical Sciences, Health Science Center, Federal University of Santa Maria, Santa Maria, RS, Brazil.

(2) University Hospital of Santa Maria, Santa Maria, RS, Brazil.

(3) Departament of Microbiology and Parasitology, Federal University of Santa Maria, Santa Maria, RS, Brazil.

Correspondence to: Prof. Dr. Sydney Hartz Alves, Rua dos Andradas 1985/201, 97010-033 Santa Maria, RS, Brazil. Phone: +55 3220-8906, E-mail: sydneyalves.ufsm@gmail.com 



from blood cultures as evaluated using the M27-A3 and new M27-S4 approved breakpoints. Rev. Inst. Med. Trop. Sao Paulo, 56(6): 477-82, 2014.

reference method for antifungal susceptibility testing that is a modification of the CLSI method ${ }^{4}$. Isolates derived from important clinical situations or sterile sites should be evaluated so that their susceptibility agents can be determined ${ }^{4}$. However, CLSI ${ }^{4}$ and EUCAST $^{25}$ standardized antifungal susceptibility tests define resistance or susceptibility based on different breakpoints.

Datasets that correlate CLSI and EUCAST MICs with outcomes revealed lower response rates when MICs were $>4 \mu \mathrm{g} / \mathrm{mL}$ for $C$. albicans, C.tropicalis and C. parapsilosis and $>16 \mu \mathrm{g} / \mathrm{mL}$ for C. glabrata. These findings led to the CLSI Subcommittee on Antifungal Susceptibility testing in an effort to harmonize the CLSI and EUCAST breakpoints for some Candida species. The new approved breakpoints (SS-CBPs) provide consistency with the EUCAST breakpoints and should be more sensitive in the detection of emerging resistance among Candida $\mathrm{spp}^{8,22}$.

Here, these two criteria for Candida spp. isolates were compared in cases of candidemia that occurred between 1995 and 2009 and were registered at the University Hospital of Santa Maria (HUSM), Santa Maria, RS, Brazil.

\section{METHODS}

1. Period of evaluation: This study evaluated the susceptibility of Candida species isolated from episodes of candidemia over 15 years (1995 to 2009).

2. Microorganisms: Four hundred and twenty-two Candida spp. strains isolated from episodes of candidemia that occurred at the University Hospital of Santa Maria (HUSM); Santa Maria, Rio Grande do Sul, Brazil. HUSM is a public, tertiary care teaching hospital with 328 beds and 10300 admissions, including adults and children, per year. The samples (blood) were collected from different wards, including adult, pediatric and neonatal intensive care units (ICU). Only one isolate of a candidemia case was included in this study.

3. Identification: Blood cultures were performed using an automated BACTEC 9120 (Becton Dickinson). Candida spp. isolated from blood agar plates were identified using standard methods, such as chlamydospore production, germ tube assays, micro-morphology studies in corn-meal-Tween 80 agar and biochemical tests using the commercial system ID32C (bioMérieux Marcy l'Etoile, France). The isolates were stored in BHI with $20 \%$ glycerol and $0.2 \%$ agar suspensions and frozen at $-70{ }^{\circ} \mathrm{C}$ until processed for the study. Before testing, each isolate was cultured on Sabouraud dextrose agar and CHROMagar to ensure purity and viability.

4. Susceptibility tests to antifungal agents: Assays for susceptibility were performed using broth microdilution according to the M27-A3 protocol of the Clinical and Laboratory Standards Institute (CLSI) ${ }^{4}$. All isolates were tested against amphotericin B (Sigma Chemical Co., St Louis, Mo), fluconazole (Sigma Chemical Co, St Louis, Mo), itraconazole (Janssen-Cilag Pharmaceutica; Belgium), flucytosine (Sigma Chemical Co), voriconazole (Pfizer, Inc) and caspofungin (Merck, Rahway, NJ), which were obtained from pure powder and prepared at the indicated concentrations according to the procedures of protocol M27-A $3^{4}$. The tests were performed in microdilution plates in which $0.1 \mathrm{~mL}$ of antifungal $2 \mathrm{X}$ concentrate was used. The microplates were then sealed with Parafilm and frozen at $-70{ }^{\circ} \mathrm{C}$ until use. The inocula were prepared from $24-48$ $\mathrm{h}$ cultures in Sabouraud dextrose agar by suspending the fungal cells in sterile, distilled water, and the turbidity was spectrophotometrically fixed according to M27-A3. Lastly, the antifungal drugs were diluted in RPMI-1640 buffered with morpholinepropanesulfonic acid (MOPS). On the day of testing, microdilution plates containing $100 \mu \mathrm{L}$ of RPMI1640 with different concentrations of antifungals were inoculated with $100 \mu \mathrm{L}$ of diluted culture, resulting in $0.5 \times 10^{3}$ to $2.5 \times 10^{3}$ cells $/ \mathrm{mL}$ in each well. The addition of this volume resulted in the required final concentration of the antifungal agents and, at the same time, the correct number of cells that were recommended in each well. The plates were closed and incubated at $35^{\circ} \mathrm{C}$ for $24-48 \mathrm{~h}$, and the MIC endpoint was determined according to document M27-A3. The susceptibility tests were interpreted according to two criteria: a) CLSI (M27-A3) and b) SS-CBPs (CLSI M27-S4) $)^{5,24}$ as shown in Table 1. Candida parapsilosis ATCC 22019 and Candida krusei ATCC 6258 were included for quality control tests, sterility control of the medium and control of the medium with antifungals ${ }^{5}$.

5. Statistical analysis: The Wilcoxon nonparametric test was used to compare two variables. Values of $p \leq 0.05$ were considered significant.

\section{RESULTS}

The study of the susceptibility of Candida spp. isolated from episodes of candidemia that occurred between 1995 and 2009 included 422 isolates that were distributed as follows: C. parapsilosis $(197 / 46.68 \%)$, C. albicans (151/35.78\%), C. tropicalis (41/9.71\%), C. glabrata $(15 / 3.55 \%)$, C. lusitaniae $(7 / 1.65 \%)$, C. guilliermondii $(7 / 1.65 \%)$ and C. krusei $(4 / 0.94 \%)$. Two hundred and seventy-one $(64.21 \%)$ isolates were grouped as Candida non-albicans species. The parameters for evaluating antifungal susceptibility (range: of susceptibility, MIC50 and MIC90) as well as the percentage of resistance that was obtained using the CLSI criteria according to M27-A3 and M27-S4 (SS-CBPs) are found in Tables 2 and 3.

When the susceptibility of all Candida isolates that were obtained from candidemia cases over 15 years was evaluated based on the CLSI M27-A3 criteria ${ }^{4}, 16$ resistant isolates were identified: itraconazole, $\mathrm{n}$ $=9($ C. albicans $=3 ;$ C. glabrata $=4 ;$ C. tropicalis $=1 ;$ C. krusei $=1)$; fluconazole, $\mathrm{n}=5($ C. glabrata $=1 ; C$. $k$ ruse $i=4)$; and voriconazole, $\mathrm{n}$ $=2($ C. glabrata $=2)$. Using the same criteria, 17 susceptible-dependentdose (SDD) or intermediate (I) isolates were found: flucytosine, $\mathrm{n}=5(C$. parapsilosis $=1$ and $C$. glabrata $=4)$; itraconazole, $\mathrm{n}=6(C$. glabrata $=3$ and $C$. krusei $=3)$; and fluconazole, $\mathrm{n}=6($ C. tropicalis $=1$ and $C$. glabrata $=5$ ). The number of non-susceptible (SDD or Intermediate plus Resistant) strains was 33 (Tables 2 and 3).

Based on the SS-CBPs (CLSI M27-S4) ${ }^{5}$, the total number of resistant isolates was 10: fluconazole, $\mathrm{n}=8$ (C. tropicalis $=3, C$. glabrata $=1$ and $C$. kruse $=4)$; and voriconazole, $\mathrm{n}=2$ (C. tropicalis). Of the susceptible dose-dependent (SDD) or Intermediate (I) isolates, $70(16.58 \%)$ were detected and distributed as follows: fluconazole, $\mathrm{n}$ $=51$ [C. albicans (15), C. parapsilosis (14), C. tropicalis (8) and C. glabrata (14)]; voriconazole, $\mathrm{n}=16$ [C. albicans (4), C. parapsilosis (7) and C. tropicalis (5)], and caspofungin $(\mathrm{n}=3)$ [C. glabrata $(3)]$. The number of non-susceptible (SDD or Intermediate plus Resistant) strains was 80 (Tables 2 and 3). 


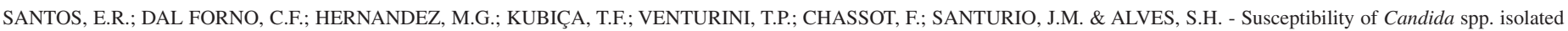
from blood cultures as evaluated using the M27-A3 and new M27-S4 approved breakpoints. Rev. Inst. Med. Trop. Sao Paulo, 56(6): 477-82, 2014.

Table 1

Interpretative breakpoints according to the MICs $(\mu \mathrm{g} / \mathrm{mL})$ from the M27-S4 and M27-A3 CLSI documents

\begin{tabular}{|c|c|c|c|c|c|c|c|}
\hline \multirow{2}{*}{ Candida Species } & \multirow{2}{*}{$\begin{array}{l}\text { Antifungal } \\
\text { agents* }\end{array}$} & \multicolumn{3}{|c|}{ M27-S4 breakpoints } & \multicolumn{3}{|c|}{ M27-A3 breakpoints } \\
\hline & & $\mathbf{S}$ & SDD & $\mathbf{R}$ & $\mathbf{S}$ & SDD & $\mathbf{R}$ \\
\hline \multirow{3}{*}{ C. albicans } & FLZ & $\leq 2.0$ & 4.0 & $\geq 8.0$ & $\leq 8.0$ & $16-32$ & $\geq 64$ \\
\hline & VOR & $\leq 0.12$ & $0.25-0.5$ & $\geq 1.0$ & $\leq 1.0$ & 2.0 & $\geq 4.0$ \\
\hline & CAS & $\leq 0.25$ & 0.5 & $\geq 1.0$ & $\leq 2.0$ & -- & -- \\
\hline \multirow{3}{*}{ C. glabrata } & FLZ & -- & $\leq 32$ & $\geq 64$ & $\leq 8.0$ & $16-32$ & $\geq 64$ \\
\hline & VOR & -- & -- & -- & $\leq 1.0$ & 2.0 & $\geq 4.0$ \\
\hline & CAS & $\leq 0.12$ & 0.25 & $\geq 0.5$ & $\leq 2.0$ & -- & -- \\
\hline \multirow{3}{*}{ C. krusei } & FLZ & -- & -- & -- & $\leq 8.0$ & $16-32$ & $\geq 64$ \\
\hline & VOR & $\leq 0.5$ & 1.0 & $\geq 2.0$ & $\leq 1.0$ & 2.0 & $\geq 4.0$ \\
\hline & CAS & $\leq 0.25$ & 0.5 & $\geq 1.0$ & $\leq 2.0$ & -- & -- \\
\hline \multirow{3}{*}{ C. parapsilosis } & FLZ & $\leq 2.0$ & 4.0 & $\geq 8.0$ & $\leq 8.0$ & $16-32$ & $\geq 64$ \\
\hline & VOR & $\leq 0.12$ & $0.25-0.5$ & $\geq 1.0$ & $\leq 1.0$ & 2.0 & $\geq 4.0$ \\
\hline & CAS & $\leq 2.0$ & 4.0 & $\geq 8.0$ & $\leq 2.0$ & -- & -- \\
\hline \multirow{3}{*}{ C. tropicalis } & FLZ & $\leq 2.0$ & 4.0 & $\geq 8.0$ & $\leq 8.0$ & $16-32$ & $\geq 64$ \\
\hline & VOR & $\leq 0.12$ & $0.25-0.5$ & $\geq 1.0$ & $\leq 1.0$ & 2.0 & $\geq 4.0$ \\
\hline & CAS & $\leq 0.25$ & 0.5 & $\geq 1.0$ & $\leq 2.0$ & -- & $>2.0$ \\
\hline C.guilliermondii & CAS & $\leq 2.0$ & 4.0 & $\geq 8.0$ & $\leq 2.0$ & -- & $>2.0$ \\
\hline
\end{tabular}

(*)FLZ = fluconazole; VOR = voriconazole; CAS = caspofungin; (--) breakpoints not provided by CLSI documents M27-S4 and M27-A3.

Based on the number of Candida spp. that were not susceptible to antifungal agents, the new SS-CBPs detected 2.4 times the number of non-susceptible isolates that were detected using the M27-A 3 breakpoints $(\mathrm{p}<0.05)$ (Table 3).

\section{DISCUSSION}

The study's results indicated minor variations in relation to the species of Candida involved in the episodes of candidemia: C. parapsilosis was the most prevalent, followed by $C$. albicans and then $C$. tropicalis. The prevalence of $C$. parapsilosis could be associated with the number of candidemia episodes that were detected in neonates and pediatric patients. HINRICHSEN et al. ${ }^{10}$ mainly reported $C$. parapsilosis in these patients. Additionally, the Candida non-albicans was more prevalent than C. albicans. These results were in accordance with those of many Brazilian studies ${ }^{6,710,19}$ and have been observed in multicentric, international studies ${ }^{23}$.

In general, the study's results showed that the detection of resistant isolates was not a common phenomenon. The definition of in vitro resistance to antifungal agents is based on the breakpoints that were established by methods standardized to yeasts in a set of CLSI documents named M27. Although the technical recommendations for performing these tests have not been changed, the interpretative breakpoints were redefined. In the CLSI M27-A3 document ${ }^{4}$, the breakpoints that define susceptible, SDD, or resistant to each antifungal agent encompass all Candida species. Recently the Subcommittee on Antifungal Susceptibility Tests of the CLSI developed new species- specific clinical breakpoints (SS-CBPs) for some Candida species (CLSI M27-S45). These new breakpoints are an attempt to balance the CLSI and EUCAST breakpoints. Thus, they took into account the distribution of MICs of the wild-type of each Candida species, the molecular mechanism of resistance, the categorical agreement between MICs that were generated by both methods (CLSI and EUCAST), as well as the reassessment of the correlation between MICs and outcome of candidemias ${ }^{8,24}$. Due to these recent advances, in the present study, the susceptibility profiles of Candida were compared using both parameters.

Based on CLSI M27-A3 ${ }^{4}$, the total number of non-susceptible isolates that were detected throughout the study was 33 (7.81\%), and, using the new breakpoints (SS-CBPs), 80 (18.95\%) isolates were non-susceptible; thus, the number of non-susceptible isolates that were identified by these different criteria differed by two-fold (Table 3).

By comparing the detection of resistance between the two interpretative criteria, a major difference in resistance identification was observed for the M27-A3 breakpoints. However, this difference was due to the presence of itraconazole, which was absent among the new M27-S4 breakpoints. On the other hand, the number of susceptible dose-dependent (SDD) or intermediate (I) isolates was increased 4-fold based on the new SS-CBPs breakpoints. The majority of susceptible dose-dependent (SDD) or intermediate (I) isolates occurred against fluconazole, which was in accordance with previous studies because fluconazole is the most common azole associated with alterations in susceptibility, and its use as an indicator of resistance to azoles has been proposed ${ }^{21}$. In this study, 
SANTOS, E.R.; DAL FORNO, C.F.; HERNANDEZ, M.G.; KUBIÇA, T.F.; VENTURINI, T.P.; CHASSOT, F.; SANTURIO, J.M. \& ALVES, S.H. - Susceptibility of Candida spp. isolated from blood cultures as evaluated using the M27-A3 and new M27-S4 approved breakpoints. Rev. Inst. Med. Trop. Sao Paulo, 56(6): 477-82, 2014.

Table 2

Susceptibility profile of Candida spp. isolated from blood cultures in 1995-2009. Detection of non-susceptible isolates based on the breakpoints from CLSI M27-A3 and species-specific clinical breakpoints from CLSI M27-S4

\begin{tabular}{|c|c|c|c|c|c|c|c|c|c|}
\hline \multirow[t]{2}{*}{ Species } & \multirow[t]{2}{*}{$\mathrm{N}$} & \multirow[t]{2}{*}{ ATF* } & \multicolumn{3}{|c|}{$\mathrm{MIC}(\mu \mathrm{g} / \mathrm{mL})$} & \multicolumn{2}{|c|}{$\begin{array}{l}\text { CLSI M27-A3 } \\
\text { Breakpoints (n) }\end{array}$} & \multicolumn{2}{|c|}{$\begin{array}{c}\text { CLSI M27-S4 } \\
\text { Breakpoints (n) }\end{array}$} \\
\hline & & & Range & MIC 50\% & MIC $90 \%$ & $\mathrm{R}$ & $\mathrm{SDD} / \mathrm{I}$ & $\mathrm{R}$ & SDD/I \\
\hline \multirow{6}{*}{ C. parapsilosis } & \multirow{6}{*}{197} & AMB & $0.06-0.5$ & 0.125 & 0.25 & 0 & 0 & -- & -- \\
\hline & & FLZ & $0.125-4.0$ & 1.0 & 4.0 & 0 & 0 & 0 & 14 \\
\hline & & ITZ & $0.03-0.5$ & 0.125 & 0.5 & 0 & 0 & -- & -- \\
\hline & & $5 \mathrm{FC}$ & $0.03-16.0$ & 0.5 & 2.0 & 0 & 1 & -- & -- \\
\hline & & VOR & $0.03-0.5$ & 0.125 & 0.25 & 0 & 0 & 0 & 7 \\
\hline & & CAS & $0.03-2.0$ & 0.5 & 2.0 & 0 & 0 & 0 & 0 \\
\hline \multirow{6}{*}{ C. albicans } & \multirow{6}{*}{151} & AMB & $0.06-1.0$ & 0.25 & 0.5 & 0 & 0 & -- & - \\
\hline & & FLZ & $0.125-4.0$ & 0.25 & 4.0 & 0 & 0 & 0 & 15 \\
\hline & & ITZ & $0.015-1.0$ & 0.25 & 0.5 & 3 & 0 & -- & -- \\
\hline & & $5 \mathrm{FC}$ & $0.03-4.0$ & 1.0 & 4.0 & 0 & 0 & -- & -- \\
\hline & & VOR & $0.015-0.5$ & 0.125 & 0.5 & 0 & 0 & 0 & 4 \\
\hline & & CAS & $0.03-0.5$ & 0.125 & 0.25 & 0 & 0 & 0 & 0 \\
\hline \multirow{6}{*}{ C. tropicalis } & \multirow{6}{*}{41} & AMB & $0.125-1.0$ & 0.125 & 0.5 & 0 & 0 & -- & - \\
\hline & & FLZ & $0.25-32.0$ & 2.0 & 8.0 & 0 & 1 & 3 & 8 \\
\hline & & ITZ & $0.03-2.0$ & 0.125 & 0.5 & 1 & 0 & -- & -- \\
\hline & & $5 \mathrm{FC}$ & $0.125-4.0$ & 1.0 & 4.0 & 0 & 0 & -- & -- \\
\hline & & VOR & $0.03-2.0$ & 0.25 & 0.5 & 0 & 0 & 2 & 5 \\
\hline & & CAS & $0.03-0.25$ & 0.06 & 0.25 & 0 & 0 & 0 & 0 \\
\hline \multirow{6}{*}{ C. glabrata } & \multirow{6}{*}{15} & AMB & $0.125-0.5$ & 0.5 & 1.0 & 0 & 0 & -- & -- \\
\hline & & FLZ & $0.5-64.0$ & 8.0 & 32.0 & 1 & 5 & 1 & 14 \\
\hline & & ITZ & $0.03-2.0$ & 0.5 & 1.0 & 4 & 3 & -- & -- \\
\hline & & $5 \mathrm{FC}$ & $0.125-16.0$ & 4.0 & 16.0 & 0 & 4 & -- & -- \\
\hline & & VOR & $0.06-4.0$ & 0.5 & 2.0 & 2 & 0 & -- & -- \\
\hline & & CAS & $0.06-0.5$ & 0.125 & 0.25 & 0 & 0 & 0 & 3 \\
\hline \multirow{6}{*}{ C. guilliermondii } & \multirow{6}{*}{7} & AMB & $0.125-0.25$ & 0.25 & 0.25 & 0 & 0 & -- & -- \\
\hline & & FLZ & $0.5-4.0$ & 2.0 & 4.0 & 0 & 0 & -- & -- \\
\hline & & ITZ & $0.03-0.5$ & 0.06 & 0.5 & 0 & 0 & -- & -- \\
\hline & & $5 \mathrm{FC}$ & $0.06-1.0$ & 0.5 & 1.0 & 0 & 0 & -- & -- \\
\hline & & VOR & $0.06-0.25$ & 0.06 & 0.06 & 0 & 0 & -- & -- \\
\hline & & $\mathrm{CAZ}$ & $0.03-0.25$ & 0.06 & 0.06 & 0 & 0 & 0 & 0 \\
\hline \multirow{6}{*}{ C. lusitaniae } & \multirow{6}{*}{7} & AMB & $0.125-0.5$ & 0.5 & 0.5 & 0 & 0 & -- & - \\
\hline & & FLZ & $0.25-4.0$ & 2.0 & 2.0 & 0 & 0 & -- & -- \\
\hline & & ITZ & $0.03-0.5$ & 0.5 & 0.5 & 0 & 0 & -- & -- \\
\hline & & $5 \mathrm{FC}$ & $0.25-2.0$ & 0.5 & 2.0 & 0 & 0 & -- & -- \\
\hline & & VOR & $0.06-0.25$ & 0.25 & 0.25 & 0 & 0 & -- & -- \\
\hline & & CAS & $0.06-0.5$ & 0.125 & 0.25 & 0 & 0 & -- & -- \\
\hline \multirow{6}{*}{ C. krusei } & \multirow{6}{*}{4} & AMB & $0.125-0.5$ & 0.25 & 0.5 & 0 & 0 & -- & -- \\
\hline & & FLZ & $4.0-8.0$ & 8.0 & 8.0 & $4 * *$ & 0 & $4 * *$ & 0 \\
\hline & & ITZ & $0.25-1.0$ & 0.5 & 0.5 & 1 & 3 & -- & -- \\
\hline & & $5 \mathrm{FC}$ & $0.25-2.0$ & 0.5 & 2.0 & 0 & 0 & -- & -- \\
\hline & & VOR & $0.06-0.25$ & 0.25 & 0.25 & 0 & 0 & 0 & 0 \\
\hline & & CAS & $0.06-0.5$ & 0.125 & 0.25 & 0 & 0 & 0 & 0 \\
\hline
\end{tabular}

(*) AMB = amphotericin B; FLZ = fluconazole; ITZ = itraconazole; $5 \mathrm{FC}=$ flucytosine; VOR = voriconazole; CAS = caspofungin; $(* *) C$. kruse $i$ are assumed to be intrinsically resistant to fluconazole; (--) breakpoints not provided by CLSI documents M27-S4 and M27-A3. 


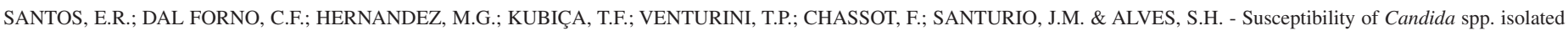
from blood cultures as evaluated using the M27-A3 and new M27-S4 approved breakpoints. Rev. Inst. Med. Trop. Sao Paulo, 56(6): 477-82, 2014.

Table 3

Comparison (number and \%) of non-susceptible Candida spp. to antifungal agents detected using the CLSI M27-A3 breakpoints and the new speciesspecific clinical breakpoints from CLSI M27-S4

\begin{tabular}{lcccc}
\hline \multirow{2}{*}{$\begin{array}{l}\text { Antifungal } \\
\text { Agents }\end{array}$} & \multicolumn{2}{c}{ M27-A3 } & \multicolumn{2}{c}{ M27-S4 } \\
\cline { 2 - 5 } & SDD & R & SDD & R \\
\hline Itraconazole & 6 & 9 & -- & -- \\
Fluconazole & 6 & 5 & 51 & 8 \\
Voriconazole & 0 & 2 & 16 & 2 \\
Flucytosine & 5 & 0 & -- & -- \\
Caspofungin & 0 & 0 & 3 & 0 \\
\hline Total & $17^{\mathrm{a}}\left(4.02^{2}\right)$ & $16(3.79 \%)$ & $70^{\mathrm{b}}(16.58 \%)$ & $10(2.36 \%)$ \\
\cline { 2 - 5 } & \multicolumn{2}{c}{$\mathbf{3 3}^{\mathrm{c}}(\mathbf{7 . 8 1 \%})$} & $\mathbf{8 0}^{\mathrm{d}}(\mathbf{1 8 . 9 5 \% )}$ \\
\hline
\end{tabular}

(--) antifungal agents not contemplated in M27-S4; (\%) referent to the total of isolates evaluated in the period $(\mathrm{n}=422) ;(\mathrm{a} \neq \mathrm{b}$ and $\mathrm{c} \neq \mathrm{d}) p<0.05$.

fluconazole resistance detected by M27-A3 was $1.18 \%$, which was similar to the results obtained by COLOMBO et al. ${ }^{6}$; on the other hand, the nonsusceptible isolates to fluconazole totaled 11 (2.60\%), which was lower than the $5 \%$ reported by COLOMBO et al. ${ }^{6}$, but similar to the $2.1 \%$ that was reported by DA MATTA et al. ${ }^{\text {. }}$.

This study detected $0.47 \%(\mathrm{n}=2)$ of isolates that were resistant to voriconazole, which is similar to the $0.2 \%$ that was reported by DA MATTA et al. ${ }^{7}$ in Brazil, but lower than the percentage reported by other authors: LYON et al. ${ }^{11}$ detected $1.1 \%$, and MESSER et al. detected $0.9 \%{ }^{12}$.

The percentage resistant to itraconazole $(2.13 \%)$ was greater than that reported by DA MATTA et al. ${ }^{7}$, but lower than the $11.5 \%$ that was reported by MESSER et al. ${ }^{12}$ and the $30 \%$ that was reported by PEMÁN et al. in Spain ${ }^{17}$.

For flucytosine, five isolates $(5 / 1.18 \%)$ were classified as intermediate (I), which is contrary to the results of DA MATTA et al. ${ }^{7}$, where $2.5 \%$ of the isolates exhibited resistance to this agent. On the other hand, most Brazilian studies did not evaluate the susceptibility of flucytosine because it is only used in combination with amphotericin B once monotherapy is no longer recommended ${ }^{18}$.

The susceptibility profile intermediate (I) to caspofungin was found for three isolates of $C$. glabrata. Although none of these were classified as resistant, the finding of this study was in accordance with that of PFALLER et al. ${ }^{23,24}$, where $C$. krusei and $C$. glabrata were the most common species, with resistances to caspofungin of $12.5 \%$ and $2.5 \%$, respectively.

In this study, the evaluation of susceptibility allows one to better understand the local epidemiology of candidemia cases that are resistant to treatment. Detecting a higher number of non-susceptible species has highlighted the importance of evaluating susceptibility tests using new SS-CBPs (CLSI M27-S45), which will impact the monitoring, selection and use of antifungal agents in the clinic.

\section{RESUMO}

\section{Suscetibilidade de Candida spp. isoladas de hemocultivos, avaliadas pelos breakpoints dos documentos M27-A3 e M27-S4 do CLSI}

As elevadas taxas de mortalidade associadas com episódios de candidemia e a emergência da resistência aos antifúngicos, requerem o monitoramento da suscetibilidade de Candida spp., isoladas das candidemias, frente aos agentes antifúngicos. Os novos breakpoints, chamados "espécie-específicos," foram recentemente aprovados (M27-S4) requerendo, pois, cuidadosa interpretação e comparações com aqueles até agora utilizados (M27-A3); ambos são propostos pelo Clinical Laboratory Standard Institute (CLSI). O presente estudo avaliou a suscetibilidade de espécies de Candida isoladas de candidemias baseando-se nestes dois breakpoints. Quatrocentos e vinte e dois isolados de Candida foram identificados e assim distribuídos: $C$. parapsilosis $(48,68 \%)$, C. albicans $(35,78 \%)$, C. tropicalis $(9,71 \%), C$. glabrata (3,55\%), C. lusitaniae (1,65\%), C. guilliermondii (1,65\%), C. krusei $(0,94 \%)$. Com base nos critérios do M27-A3, um total de 33 $(7,81 \%)$ isolados foram julgados não-sensíveis, dos quais $16(3,79 \%)$ como resistentes aos antifúngicos. De acordo com os breakpoints espécie-específicos (M27-S4) um total de $80(18,95 \%)$ isolados foram considerados não-sensíveis, dos quais $10(2,36 \%)$ resistentes a algum dos antifúngicos testados. Com base nos novos breakpoints espécieespecíficos, o número de isolados não-sensíveis foi 2,4 vezes maior do que o número de não-sensíveis detectado pelos breakpoints do documento M27-A3. A detecção de um elevado número de isolados não-sensíveis através dos breakpoints propostos pelo M27-S4 destaca a importância dos testes de suscetibilidade, os quais trarão impactos no reconhecimento de isolados de Candida spp. não-sensíveis em episódios de candidemias, requerendo, portanto, continua avaliação.

\section{ACKNOWLEDGMENTS}

To CNPq and FAPERGS (Fundação de Amparo à Pesquisa do Estado do Rio Grande do Sul).

\section{REFERENCES}

1. Almirante B, Rodríguez D, Park BJ, Cuenca-Estrella M, Planes AM, Almela M, et al. Epidemiology and predictors of mortality in cases of Candida bloodstream infection: results from population-based surveillance, Barcelona, Spain, from 2002 to 2003. J Clin Microbiol. 2005;43:1829-35.

2. Antunes AGV, Pasqualotto AC, Diaz MC, d'Azevedo PA, Severo LC. Candidemia in a Brazilian tertiary care hospital: species distribution and antifungal susceptibility patterns. Rev Inst Med Trop Sao Paulo. 2004;46:239-41.

3. Aquino VR, Lunardi LW, Goldani LZ, Barth AL. Prevalence, susceptibility profile for fluconazole and risk factors for candidemia in a tertiary care hospital in southern Brazil. Braz J Infect Dis. 2005;9:411-8.

4. Clinical and Laboratory Standards Institute. (CLSI). Reference method for broth dilution antifungal susceptibility testing of yeasts. $3^{\text {rd }}$ ed. Wayne: Clinical and Laboratory Standards Institute; 2008. (Approved standard. M27-A3).

5. Clinical and Laboratory Standards Institute. (CLSI). Reference method for broth dilution antifungal susceptibility testing of yeasts; fourth informational supplement. Wayne: Clinical and Laboratory Standards Institute; 2012. (Document M27-S4). 
SANTOS, E.R.; DAL FORNO, C.F.; HERNANDEZ, M.G.; KUBIÇA, T.F.; VENTURINI, T.P.; CHASSOT, F.; SANTURIO, J.M. \& ALVES, S.H. - Susceptibility of Candida spp. isolated from blood cultures as evaluated using the M27-A3 and new M27-S4 approved breakpoints. Rev. Inst. Med. Trop. Sao Paulo, 56(6): 477-82, 2014.

6. Colombo AL, Nucci M, Park BJ, Nouér SA, Arthington-Skaggs B, da Matta DA, et al. Epidemiology of candidemia in Brazil: a nationwide sentinel surveillance of candidemia in eleven medical centers. J Clin Microbiol. 2006;44:2816-23.

7. Da Matta DA, de Almeida LP, Machado AM, Azevedo AC, Kusano EJU, Travassos NF, et al. Antifungal susceptibility of 1000 Candida bloodstream isolates to 5 antifungal drugs: results of a multicenter study conducted in São Paulo, Brazil, 1995-2003. Diagn Microbiol Infect Dis. 2007;57:399-404

8. Diekema DJ, Pfaller MA. Utility of antifungal susceptibility testing and clinical correlations. In: Hall GS, editor. Interactions of yeasts, moulds, and antifungal agents: how to detect resistance. New York: Springer Science+Business Media; 2012. p. 131-58.

9. França JCB, Ribeiro CEL, Queiroz-Telles F. Candidemia em um hospital terciário brasileiro: incidência, freqüência das diferentes espécies, fatores de risco e suscetibilidade aos antifúngicos. Rev Soc Bras Med Trop. 2008;41:23-8.

10. Hinrichsen SL, Falcão E, Vilella TAS, Colombo AL, Nucci M, Moura L, et al. Candidemia em hospital terciário no nordeste do Brasil. Rev Soc Bras Med Trop. $2008 ; 41: 394-8$

11. Lyon GM, Karatela S, Sunay S, Adiri Y. Candida Surveillance Study Investigators. Antifungal susceptibility testing of Candida isolates from the Candida surveillance study. J Clin Microbiol. 2010;48:1270-5.

12. Messer SA, Moet GJ, Kirby JT, Jones RN. Activity of contemporary antifungal agents, including the novel echinocandin anidulafungin, tested against Candida spp., Cryptococcus spp., and Aspergillus spp.: report from the SENTRY Antimicrobial Surveillance program (2006-2007). J Clin Microbiol. 2009;47:1942-6.

13. National Committee for Clinical Laboratory Standards (NCCLS). Reference method for broth dilution antifungal susceptibility testing yeasts. Wayne:National Committee for Clinical Laboratory Standards; 1997. (Approved standard document M27-A).

14. Olaechea PM, Palomar M, León-Gil C, Alvarez-Lerma F, Jordá R, Nolla-Salas J, et al. Economic impact of Candida colonization and Candida infection in the critically ill patients. Eur J Clin Microbiol Infect Dis. 2004;23:323-30.

15. Pappas PG, Kauffmann CA, Andes D, Benjamin DK Jr, Calandra TF, Edwards JE Jr, et al. Clinical practice guidelines for the management of candidiasis: 2009 update by the Infectious Diseases Society of America. Clin Infect Dis. 2009;48:503-35.

16. Pasqualotto AC, Nedel WL, Machado TS, Severo LC. A 9-year study comparing risk factors and outcome of pediatric and adults with nosocomial candidaemia. Mycopathologia. 2005;160:111-6.
17. Pemán J, Cantón E, Gobernado M, Spanish ECMM Working Group on Candidaemia. Epidemiology and antifungal susceptibility of Candida species isolated from blood: results of a 2 -year multicenter study in Spain. Eur J Clin Microbiol Infect Dis. $2005 ; 24: 23-30$.

18. Pemán J, Cantón E, Espinel-Ingroff A. Antifungal drug resistance mechanisms. Expert Rev Anti Infect Ther. 2009;7:453-60

19. Pereira GH, Muller PR, Szeszs MW, Levin AS, Melhem MSC. Five-year evaluation of bloodstream yeast infections in a tertiary hospital: the predominance of non- $C$. albicans Candida species. Med Mycol. 2010;48:839-42.

20. Pfaller MA, Diekema DJ. Epidemiology of invasive candidiasis: a persistent public health problem. Clin Microbiol Rev. 2007;20:133-63.

21. Pfaller MA, Messer SA, Boyken L, Rice C, Tendolkar S, Hollis RJ, et al. Use of fluconazole as a surrogate marker to predict susceptibility and resistance to voriconazole among 13,338 clinical isolates of Candida spp. tested by clinical and laboratory standards institute-recommended broth microdilution methods. J Clin Microbiol. 2007;45:70-5

22. Pfaller MA, Andes D, Diekema DJ, Espinel-Ingroff A, Sheehan D, CLSI Subcommittee for Antifungal Susceptibility Testing. Wild-type MIC distributions, epidemiological cutoff values and species-specific clinical breakpoints for fluconazole and Candida: time for harmonization of CLSI and EUCAST broth microdilution methods. Drug Resist Updat. 2010;13:180-95.

23. Pfaller MA, Messer SA, Moet GJ, Jones RN, Castanheira M. Candida bloodstream infections: comparison of species distribution and resistance to echinocandin and azole antifungal agents in Intensive Care Unit (ICU) and non-ICU settings in the SENTRY Antimicrobial Surveillance Program (2008-2009). Int J Antimicrob Agents. 2011;38:65-9.

24. Pfaller MA, Diekema DL. Progress in antifungal susceptibility testing of Candida spp by use of Clinical and Laboratory Standards Institute broth microdilution methods, 2010 to 2012. J Clin Microbiol. 2012:2846-56.

25. Rodriguez-Tudela JL, Arendrup MC, Barchiesi F, Bille J, Chryssanthou E, Cuenca-Estrella M, et al. EUCAST definitive document EDef 7.1: method for the determination of broth dilution MICs of antifungal agents for fermentative yeasts. Clin Microbiol Infect. 2008;14:398-405.

Received: 16 October 2013

Accepted: 22 April 2014 